

\section{Panta Rei \\ Revista Digital de Ciencia \\ y Didáctica de la Historia}

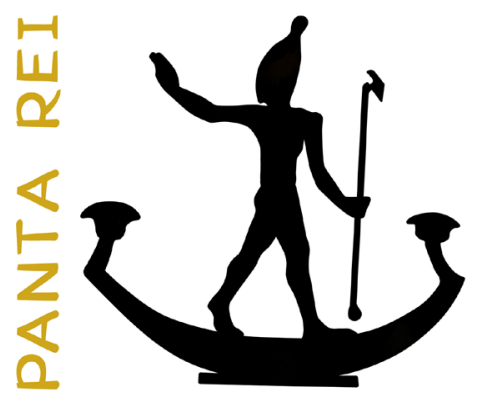

2017

Revista anual

Fecha de inicio: 1995

Revista Panta Rei. pantarei@um.es

Edita:

Centro de Estudios del Próximo Oriente y la

Antigüedad Tardía - CEPOAT

Edificio Universitario Saavedra Fajardo.

Universidad de Murcia

C/ Actor Isidoro Máiquez, 9

30007 - MURCIA - ESPAÑA

Teléfono: (+34) 868883890

cepoat@um.es

Web: www.um.es/cepoat/pantarei

Edición 2017

ISSNe: 2386-8864

ISSN: 1136-2464

Depósito legal: MU-966-1995
cepoAt

UNIVERSIDAD DE MURCIA centro de estudios del próximo oriente y la antigüedad tardia

En Portada: Kaaba durante el Ramadán. Fotografía de Abdullah Shakoor. Creative Commons CCO.

Responsables de los textos: Sus autores.

Responsable de la presente edición: Consejo Editorial Panta Rei. 


\section{CONSEJO DE REDACCIÓN}

\section{Coordinador editorial}

Egea Vivancos, Alejandro

[Didáctica de las Ciencias Sociales, UMU]

\section{Editores}

Botí Hernández, Juan Jesús

[CEPOAT, UMU]

Meseguer Gil, Antonio José

[UNED]

Sáez Giménez, David Omar

[CEPOAT, UMU]

Sánchez Mondéjar, Celso Miguel

[Patrimonio Inteligente]

\section{Secretaria}

Arias Ferrer, Laura

[Didáctica de las Ciencias Sociales, UMU]

\section{Responsable informático}

Martínez García, José Javier

[CEPOAT, UMU]

\section{Traducción y corrección lingüística}

Martínez Martínez, Cristina

[Sociedad Española de Lenguas Modernas]

Albaladejo Albaladejo, Sara

[ISEN, UMU]

\section{CONSEJO ASESOR}

Albero Muñoz, M. ${ }^{a}$ del Mar

[H. ${ }^{a}$ del Arte, UMU]

Chapman, Arthur

[History Education, UCL, Reino Unido]

Cobacho López, Ángel

[Derecho, UMU]

Egea Bruno, Pedro M. ${ }^{a}$

[Historia Contemporánea, UMU]

García Atienzar, Gabriel

[Prehistoria, UA]

González Monfort, Neus

[Didáctica de las Ciencias Sociales, UAB]

Haber Uriarte, María

[Prehistoria, UMU]

Hutson, Scott R.

[Anthropology, UK, EEUU]

Irigoyen López, Antonio

[Historia Moderna, UMU]

Mahony, Simon

[Digital Humanities, UCL, Reino Unido]

Marsilla de Pascual, Francisco Reyes

[Técnicas historiográficas, UMU]

Miralles Maldonado, José Carlos

[Filología Clásica, UMU]

Molina Gómez, José Antonio

[Historia Antigua, UMU]

Noguera Celdrán, José Miguel

[Arqueología, UMU]

Pérez Molina, Miguel Emilio

[Filología Clásica, UMU]

Prados Martínez, Fernando

[Arqueología, UA]

Sánchez Ibáñez, Raquel

[Didáctica de las Ciencias Sociales, UMU]

Sancho Gómez, Miguel Pablo

[Educación, UCAM]

Vilar García, María José

[Historia Contemporánea, UMU]

Zamora López, José Ángel

[Próximo Oriente Antiguo, CCHS-CSIC] 

Artículos

Entre el mito y la historia: el Éxodo de los israelitas desde Egipto a Canaán.

David Villar Vegas.

El Cerro de la Ermita de La Encarnación (Caravaca de la Cruz, Murcia): santuario y territorio en el mundo ibérico del Sureste peninsular.

Leticia López-Mondéjar.

Estelas discoideas y mundo funerario en la Asturias antigua.

Narciso Santos Yanguas......

Filosofía y paganismo en las postrimerías del Imperio Romano de Occidente. El caso del cónsul Mesio Febo Severo.

Rafael González Fernández y Miguel Pablo Sancho Gómez.

Dinámicas identitarias en el Mundo Actual: la religión como identidad frente al otro.

Rafael Ruiz Andrés y Francisco Javier Fernández Vallina.

El patrimonio fenicio-púnico. Claves para su socialización, puesta en valor y uso didáctico.

Helena Jiménez Vialás.

¿Cómo se enseña la llustración en $22^{\circ}$ de Bachillerato? Un análisis de los libros de texto, sus contenidos y la cuestión de género.

Helena Rausell Guillot..... 109

The Role of Local History in Elementary and Secondary Schools in Slovenia: An Evaluation of the Centre for School and Outdoor Education.

Danijela Trškan

Reseñas

Richardson, S. y Garfinkle, S. (eds.) (2016). Scholarship and Inquiry in the Ancient Near East (=Journal of Ancient Near Eastern History special issue, vol. 2/2, 2015) Berlin: de Gruyter. 179 págs.

Juan Álvarez García.

Guldi, J. y Armitage, D. (2016). Manifiesto por la Historia (traducción de Galmarini, M. A. The History Manifesto, 2014). Madrid: Editorial Alianza. 292 págs.

Juan Jesús Botí Hernández y David Omar Sáez Giménez.....

Normas de publicación/Publishing rules 



\title{
Estelas discoideas y mundo funerario en la Asturias antigua
}

\author{
Discoidal stelae and funerary world in the ancient Asturias
}

Narciso Santos Yanguas ${ }^{1}$

Universidad de Oviedo

Recibido: $15 / 07 / 2016$

Aceptado: 05/07/2017

Para citar este artículo: Santos Yanguas, N. (2017). Estelas discoideas y mundo funerario en la Asturias antigua. Panta Rei. Revista Digital de Ciencia y Didáctica de la Historia, 41-57.

ISSNe: $2386-8864$

DOI: $10.6018 /$ pantarei/2017/3

\section{Resumen}

Se realiza un repaso a una decena de monumentos epigráficos antiguos, relacionados más o menos directamente con estelas discoideas, aparecidos a lo largo de la geografía de Asturias. Se diferencia entre la estela de Coaña y otros monumentos anepígrafos, epitafios inmersos en un disco solar y, por último, el caso particular de la lápida de Superia que se vincula a las estelas discoideas. En todos los casos, su origen y funcionalidad se relacionan con el mundo funerario. Se defiende la hipótesis de que este conjunto de documentos pudiera vincularse en un primer momento con aspectos astrales, pues constituyen una representación solar, si bien su significado pueda ir más allá y relacionarse con el mundo funerario de estas culturas.

\section{Palabras clave}

Historia de Europa, Arqueología, Religión, Cristianismo.

\section{Abstract}

A review of about ten ancient epigraphical monuments is made. These are more or less related with discoid stelae, which can be found throughout Asturias geography. A differentiation is made between the Coaña stele and other anepigraphical monuments, epitaphs enclosed in a solar disc and, lastly, the particular case of the Superia gravestone, which is linked to the discoid stelae. In all cases, its origin and functions are related to the funerary world. A hypothesis about the ensemble of these documents being initially linked to astral aspects is advocated, as they constitute a solar representation, even if their meaning could go beyond and being related to the funerary world of these cultures.

\section{Key words}

European History, Archaeology, Religion, Christianity.

1 Para contactar con el autor: Narciso Santos Yanguas. Universidad de Oviedo. Departamento de Historia. nsantos@uniovi.es. 


\section{Introducción}

Uno de los mayores problemas vinculados a la cultura castreña del Noroeste peninsular, por no decir el más difícil de resolver hasta la actualidad, lo constituye el correspondiente al lugar de enterramiento de los habitantes de los recintos fortificados, a pesar de que exista cierta coincidencia entre los investigadores a la hora de asignarles la práctica de la incineración de los cadáveres para tales fines.

Tal vez la ubicación originaria de las estelas discoideas en tiempos prerromanos nos permita aproximarnos a dicha realidad, teniendo en cuenta que la localización primitiva de las mismas pudo haber tenido mucho que ver con la asociación existente entre los cultos relacionados con el sol y las creencias vinculadas al mundo de ultratumba. En este sentido, en nuestra opinión, para las poblaciones astures el astro solar, figurado en las estelas discoideas, significaba sin duda el nexo de unión entre el cielo y la tierra, entre este mundo y el otro (el del más allá tras la muerte).

Este tipo de monumentos más antiguos (fases históricas prerromana y romana), al igual que sucederá después en el momento en que el cristianismo asimile esos mismos objetivos relacionados con la otra vida, revestiría unas características funerarias claramente definidas y singulares, de manera que en los siglos posteriores se produciría un cierto continuismo en esas mismas funciones.

Ahora bien, en las páginas siguientes no pretendemos llevar a cabo un análisis completo de esta clase de documentos aparecidos en otras regiones distintas a la asturiana, por lo que no haremos hincapié en estudios monográficos de zonas como Navarra o la Meseta norte, ya que esas estelas discoideas medievales no constituyen, desde nuestro planteamiento inicial, más que el final de un proceso que abarca todo el ámbito geográfico del Norte peninsular y nuestro estudio se centra en un simple recorrido de ámbito local (el territorio de Asturias durante la Antigüedad). Ello nos exime de tener que recurrir a la ingente bibliografía existente al respecto sobre los documentos medievales de carácter cristiano descubiertos hasta la actualidad, tanto en la zona de Navarra como en las regiones circundantes, especialmente en la provincia de Soria, sin la obligación de revisar las Actas de los Congresos sobre estelas funerarias celebrados hasta la fecha.

Y todo ello a pesar de que, en el caso de Asturias, no disponemos hasta nuestros días de ejemplos correspondientes a estelas discoidales de época visigodo-medieval (Diego Santos, 1994), al contrario de lo que sucede por ejemplo en el caso del territorio de la Cantabria actual (Bohigas et al. 2004).

Sin embargo, frente a la abundante decoración (en ocasiones profusa) que se registra en sus dos caras en el caso de las piezas cristianas de tiempos medievales, los ejemplares correspondientes a la Asturias antigua no presentan esa figuración; es más, nos hallamos en ocasiones ante monumentos anepígrafos, que sobresalen, no por su iconografía sino por su morfología (se identifican con grandes megalitos que disponen de un vástago para hincar en el suelo y un remate en su parte superior en forma de círculo), derivada en gran medida de la simbología que encierran.

Apenas una decena de monumentos epigráficos antiguos, asimilados directa o indirectamente a estelas discoideas, han aparecido en diversos enclaves del actual territorio de Asturias, cuyo origen y funcionalidad se relacionan con el mundo funerario.

Este conjunto de documentos parece vincularse en un primer momento con aspectos astrales en tanto que constituyen una clara representación del sol, a pesar de que su significado puede ir más allá al contextualizarse en un mundo vinculado con la muerte y las costumbres funerarias (Santos, 2016b).

La presencia de esta clase de monumentos en los alrededores de los recintos castreños (pues no parece que formaran parte del contexto poblacional de los mismos) nos lleva a considerar su asociación con posibles lugares de enterramiento de los habitantes de los centros de población antiguos, especialmente en la época anterior a la presencia romana: esa finalidad funeraria implicaría no tanto la señalización directa de las tumbas de los difuntos de manera individual, cuanto la existencia en su entorno de un espacio dedicado a enterramientos colectivos, que vendría marcado precisamente por la presencia de una o varias de tales piezas. 
En su origen se trataría de documentos sin campo epigráfico en ninguna de sus superficies, como podemos observar en el correspondiente a Coaña, o bien en el descubierto en las proximidades de Santibáñez de la Fuente (concejo de Aller) que, en la actualidad se encuentra depositado en el museo privado Tabularium Artis Asturiensis, desconociéndose a qué recinto de población de época castreña estaría vinculado. Lo mismo sucede con la estela de Duesos (concejo de Caravia), aunque en este caso se identifica con un monumento intensamente decorado con círculos en entrelazo (Diego Santos, 1985), sin duda en conexión con algún recinto castreño, de tiempos prerromanos y/o romanos. Dicha profusión decorativa parece relacionarse más con la época romana que con la prerromana, quizás vinculada más al tipo de decoración que encontramos en las estelas gigantes de Cantabria (Peralta, 2004).

Con el paso del tiempo, ya en una segunda fase (época romana), ese proceso de asociación entre el culto naturalista al sol y el mundo funerario y del más allá parece concretarse en la representación de figuras humanas en el marco del círculo solar, como, por ejemplo, en la lápida funeraria de Superia (san Juan de Beleño, concejo de Ponga) (Santos, 2013).

Este proceso puede observarse igualmente en las dos inscripciones descubiertas en La Lloraza (concejo de Villaviciosa), la primera de las cuales parece acoger en el disco solar el epitafio de un difunto, mientras que la segunda (lápida sepulcral de Aravo) en realidad no se corresponde con una estela discoidea, aunque sus características y la representación de dos círculos (solares y/u oculares) en su parte superior tal vez fuese la derivación última de dicho proceso en tiempos romanos.

A este respecto, sin duda el mejor ejemplo de contenido epigráfico rodeado por un disco solar, con las connotaciones propias del mundo funerario y de ultratumba, lo descubrimos en la estela de Bovecio (Collía, concejo de Parres), en la que el epitafio aparece rodeado por un círculo rebajado. Se trata de un documento fragmentado en su parte inferior, que sin duda sería utilizado para hincarse en tierra (Santos, 2016a).

\section{El caso singular de la estela de Coaña y los monumentos anepígrafos}

En primer lugar, y como exponente más notorio, hemos de destacar la estela discoidea vinculada al recinto castreño de El Castelón o Castrillón (Villacondide, concejo de Coaña) (anepígrafa y sin ningún tipo de representación o decoración, por lo que se la puede considerar anicónica, al menos en cuanto que no cuenta con ningún elemento figurado en su superficie). En este caso, la figuración relacionada con el sol se reduce exclusivamente a la forma de la piedra.

Los avatares de esta pieza, desde su descubrimiento, han sido múltiples (Diego Santos, 1985). Fue encontrada en posición horizontal (caída en el suelo) y en torno a 1922 se erigió verticalmente, tal y como se conserva en la actualidad a la entrada del pueblo de Llosoiro, aunque hasta mediados del siglo pasado parece haber estado ubicada en las proximidades del acceso al poblado antiguo mencionado (Figura 1). Se la conoce popularmente como "Piedra de Nuestra Señora", sin duda a causa de ese proceso de sincretismo entre los cultos paganos más antiguos asociados a los castros y la cristianización que se produciría hace muchos siglos (desde el VI al menos, o tal vez con anterioridad) en todo el arco noroccidental hispano.

El disco superior del monumento se corresponde con un diámetro de alrededor de $1,50 \mathrm{~m}$. al tiempo que el soporte de la misma se aproxima a $1 \mathrm{~m}$., hallándose hundido en el suelo otros $50 \mathrm{~cm}$. más o menos (el monumento tiene un grosor en torno a $23 \mathrm{~cm}$.); de las dos caras del documento una se halla pulimentada mientras que la otra no, manifestándose sin labrar, toscamente cortada y de forma cóncava.

A simple vista nos ofrece ciertas similitudes (aunque sin decoración alguna) con las que el padre Carballo denominó "estelas gigantes de Cantabria" (Carballo, 1948), por lo que, tanto por su morfología como por sus dimensiones, resulta comparable a las dos de Lombera, a la de Corrales de Buelna, a la de Barros y a la de Zurita, esta última con un diámetro de más de $2 \mathrm{~m}$. (de hecho, por ejemplo, una de las estelas de Lombera se descubrió y estaba asociada a la derruida ermita de 
San Cipriano en el valle de Buelna) (Gómez Ortiz, 1938).

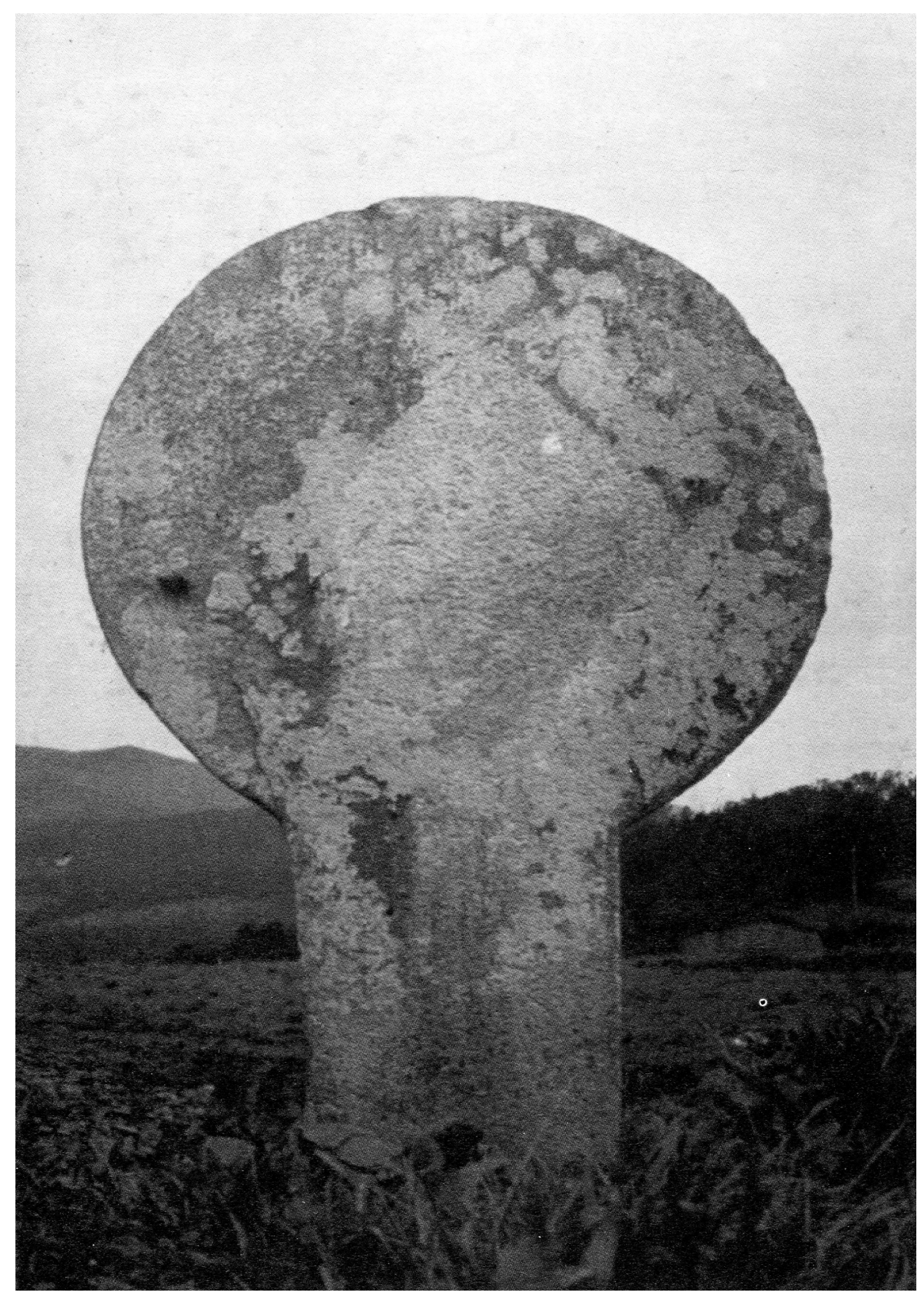

Figura 1: Estela discoidea asociada al recinto castreño de Coaña (Llosoiro, Coaña) (Diego Santos, 1985).

Sin embargo, hay que destacar una diferencia sustancial entre el ejemplar de Coaña y los correspondientes a las estelas discoideas cántabras, consistente en la ausencia de decoración en el caso de la de Asturias, quizás porque esta última se feche en una fase histórica más antigua (en todo caso de tiempos prerromanos), apoyada precisamente en esa ausencia de figuración alguna en su superficie (Peralta, 1996).

¿Y si las estelas gigantes discoideas de Cantabria no son tan antiguas (prerromanas) como la 
de Coaña sino medievales, o corresponden ya a la última fase de la Antigüedad, es decir a la etapa visigodo-cristiana, o la etapa romana, como pudo ser el caso de la estela discoidea de Caravia en Asturias? Aunque tradicionalmente se ha venido considerando que las estelas discoideas de Cantabria deben asignarse a un ámbito cronológico que va del siglo I a.C. al siglo I d.C. (Bohigas et al., 2004; Peralta, 2004) otros investigadores consideran que tal vez deban adscribirse a tiempos tardorromanos o medievales (Cerezo y Vega, 2004).

Su profusión decorativa recuerda, y parece vincularse más, aunque difícilmente se pueda identificar con la figuración deformada de la cruz, con la correspondiente a las estelas cristianas (bajoimperiales, visigodas y medievales) del Norte peninsular; y más aún si tenemos en cuenta su asociación con centros cristianos de culto (¿se compagina así el significado solar con el sentido cristiano de la vida?).

Unas características similares (misma tipología como estela discoidea) nos presenta el documento anepígrafo de la localidad de Santibáñez de la Fuente (concejo de Aller), en la actualidad conservado en una colección privada de Oviedo, que se identifica con un vástago cada vez más rebajado sobre el que descansa una estela discoidea comparable a la de Coaña.

La no presencia de letra escrita alguna, unido a sus rasgos morfológicos, nos lleva a pensar que, como en el caso anterior, quizás serviría como indicativo del lugar de enterramiento colectivo de las cenizas correspondientes a los habitantes de alguno de los recintos castreños próximos a su lugar de descubrimiento (Diego Santos, 1985).

Quizás corresponda a esta misma fecha (época prerromana) el ejemplar de estela discoidea hallado en Duesos, concejo de Caravia (Fernández y Miyares, 1987), a pesar de que nos presenta algunas diferencias evidentes con respecto a la de Coaña: el monumento fue encontrado en la parte externa de la iglesia de dicha población, hallándose configurada sobre un bloque de cuarcita (Santos, 2017).

La vinculación con este edificio de culto cristiano constituye una realidad relativamente frecuente en el suelo de Asturias ( $y$ algo parecido parece suceder con respecto a Cantabria) como consecuencia del proceso de cristianización experimentado por lugares de culto pagano de la etapa histórica anterior al arraigo de la nueva doctrina.

Desgraciadamente se ha tenido que llevar a cabo una reconstrucción del original, cuya parte inferior del vástago, que serviría para su hundimiento en el suelo, se encuentra fracturado en la actualidad (Figura 2).

A pesar de que ciertos aspectos parecen relacionarla con el arte indígena castreño, unido a su carácter anepígrafo (sin que nos muestre ninguna otra prueba de romanización), por lo que se ha asignado su cronología a la fase anterromana (Fernández y Miyares, 1987) y que la presencia de lazos entrelazados se recoja en otras lápidas, como las de Valduno (concejo de Las Regueras) y Castiello (Doriga, Cornellana, concejo de Salas), fechadas ya en época romana, tal vez su tipología nos acerque más a una etapa avanzada de la historia romana relacionada con los tiempos bajoimperiales, por lo que nos encontraríamos al final del proceso evolutivo que estamos analizando. Cabe recordar que la fragmentación del monumento no nos permite comprobar si en el vástago se daba acogida a un campo epigráfico desconocido, tal vez correspondiente a un epitafio en el ámbito religioso-funerario que estamos analizando.

Por otro lado esta pieza parece acercarse, en cuanto a su iconografía, mucho más a las características que nos ofrecen las conocidas como "estelas gigantes de Cantabria", aunque su decoración no es similar: el disco superior nos presenta en su parte central la figuración del sol (con los rayos a través de la representación de una rueda dextrógira), rodeado a su vez por un círculo de nudos entrelazados, semejantes al conocido como "nudo de Salomón" (esvásticas múltiples de rayos curvos). Esta misma iconografía se halla representada en el enlace entre el disco superior y la base (vástago) de la pieza, donde podemos observarlo, tal vez algo ampliado, en forma de un 8 en posición horizontal.

Habría que relacionarla ya con las estelas propias de la Asturias romana, aunque manteniendo unas tradiciones indígenas astures evidentes, especialmente si tenemos en cuenta que, entre los 
restos materiales que se han obtenido de las excavaciones del denominado castro de Caravia, se han recuperado elementos decorativos similares a los que nos refleja dicho monumento. En este sentido, tal vez por ello cabe la hipótesis de que, al igual que hemos apuntado que sucedería en el caso del castro de Coaña, podría existir una relación directa entre dicho monumento y el mundo funerario de los habitantes de dicho recinto de población.

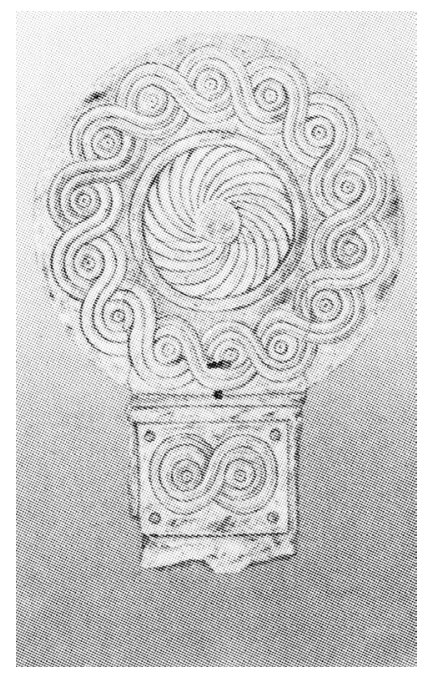

Figura 2: Reconstrucción de la estela discoidea de Duesos (Caravia) (Fernández y Miyares, 1987).

Sin embargo, esta figuración decorativa no es exclusiva de este documento sino que se refleja igualmente en otras inscripciones romanas de Asturias, como la correspondiente a la estela funeraria de la hija de Tálavo, hallada en Cornellana (concejo de Salas) ${ }^{2}$, o bien la dedicada a Sestio Munigálico, encontrada frente al pórtico de la iglesia de Santa Eulalia de Valduno (concejo de Las Regueras) (Fernández Fuster, 1952).

En ambos casos existe una diferencia muy notable, pues en la dedicatoria de Cornellana se enmarca en el círculo que figura el disco solar no solo la representación antropomorfa de la difunta sino también el campo epigráfico correspondiente, mientras que en la inscripción de Valduno, aunque sin representación antropomorfa alguna, se describe perfectamente, en plano rebajado, la cartela perteneciente a dicho campo.

\section{Epitafios inmersos en el disco solar}

De características excepcionales, pese a su estado fragmentado (se conservan dos de los cuatro trozos que parecen haber configurado la pieza en su conjunto) (González, 1951), el documento descubierto en la localidad de Castiello (Cornellana, concejo de Salas), en un caserío próximo a un antiguo poblado castreño, nos presenta un fragmento mayor, correspondiente a la mitad derecha y conservado en el palacio de los Selgas (EI Pito, concejo de Cudillero) mientras que el de la izquierda, menor y sin rasgos de letras inscritas (exclusivamente ornamental y figurativo), se encuentra depositado en la actualidad en el Museo Arqueológico Provincial de Oviedo. Las dimensiones correspondientes al primer fragmento son de unos $160 \mathrm{~cm}$. de alto por 60 de ancho, mientras que las del segundo, que encaja con el anterior, son de $123 \mathrm{~cm}$. de alto por 49 de ancho, lo que nos daría una altura total del monumento en su origen de unos 2,20 m. Como ya propusiera Hübner, podemos admitir que se trataría del epitafio de Pelsina, hija de Tálavo y mujer de Rectugeneo, aunque ninguno de estos antropónimos esté documentado con claridad en las inscripciones romanas de Asturias, al contrario de lo que sucede con Tálavo, cuyo nombre

2 CIL II, 5750: [Pelsin]ae? Talavi f(iliae)/ [Rectuge]nei? uxsori. 
alterado (Tabalus) es posible reconocer en el epitafio de su hijo Cesarón hallado en san Miguel de Liño (Oviedo) (sobre Tabalus remitimos a Abascal, 1994) .

Ahora bien, algunos elementos recogidos en el campo epigráfico del monumento (como la falta del encabezamiento D.M. la no confirmación de los años de la difunta y la ausencia del formulario funerario final H.S.E. entre otros) ha llevado a pensar en su datación en una época antigua (décadas finales del siglo I d.C.) (Figura 3).

Lo más sobresaliente de este documento se vincula sin duda con su iconografía como ya dio cuenta Diego Santos (1985, p. 82): "gracias al fragmento del Museo se completa que, debajo de la inscripción, adornan y cubren el frente de la lápida 4 anchas franjas horizontales, separadas entre sí por un estrecho listón". Cada una de estas franjas dispone a su vez de dos conjuntos de cintas en relieve entretejidas, configurando un entrelazo con motivos diferentes (Millán, 1941).

Mucho más sobresaliente resulta el hecho de que la figura antropomorfa de la mujer y el campo epigráfico se hallen envueltos en una especie de nicho, al que rodea, como el arco de la estela, una amplia cenefa, en la que se entrecruzan unos haces en relieve; por lo que concierne al rostro de la dama, además de que destaca por encima del campo epigráfico como un relieve, aparece representado con una sonrisa muy expresiva, tal vez como manifestación del elevado nivel logrado por las figuraciones artísticas de los astur-romanos (Jordá, 1977).

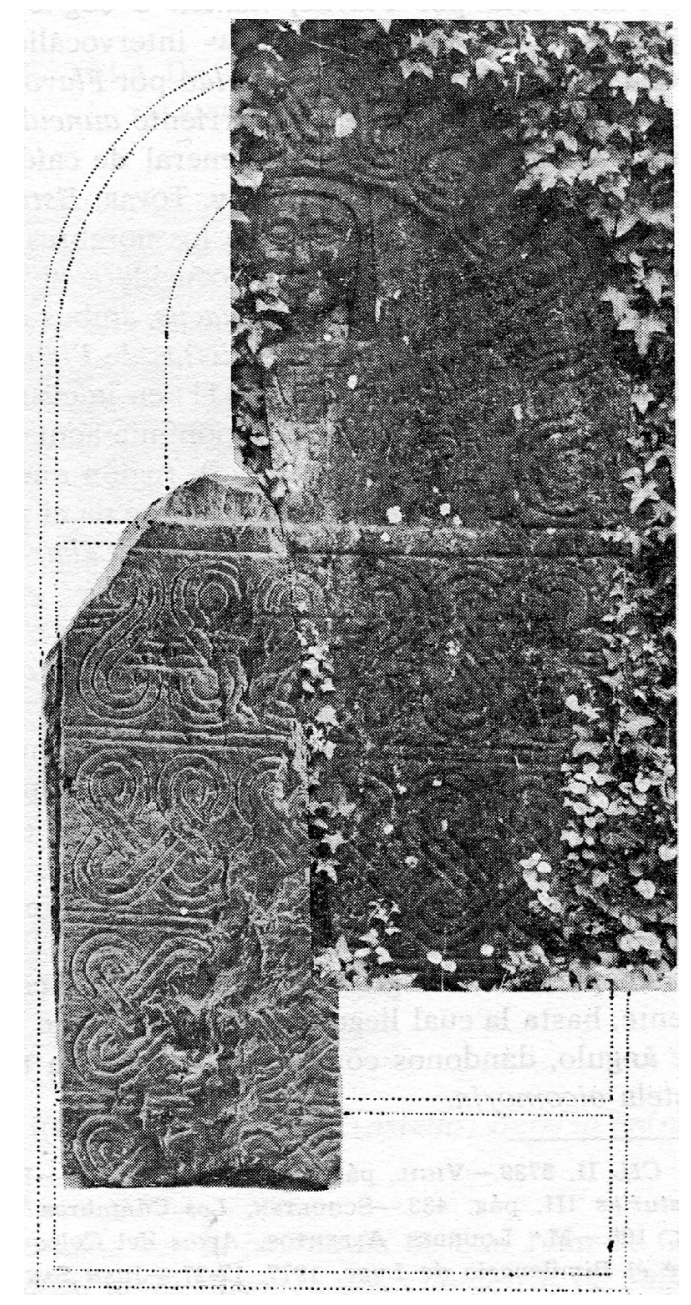

Figura 3: Lápida funeraria de la hija de Tálavo (Cornellana, Salas) (Diego Santos, 1985).

3 CIL II, 2700: Caes/ aron/ i Taba/ li f(ilio). 
En un contexto similar (características funerarias y tipología de entrelazo en forma de círculo rodeando el campo epigráfico) se halla la estela, quizás también funeraria, encontrada frente al pórtico de la iglesia de Santa Eulalia de Valduno (concejo de Las Regueras). Nos encontramos ante una piedra de caliza, propia de la región, fragmentada en su parte baja (solo incumbe muy parcialmente al inicio de la última línea del campo epigráfico) y con un remate en arco en su zona superior. Mide $128 \mathrm{~cm}$. de alto por 90 de ancho y 33 de grueso (las letras entre 5 y $6 \mathrm{~cm}$.), mientras que el recuadro que circunvala la inscripción alcanza $45 \mathrm{~cm}$. por cada lado. Por su parte, la cronología del documento hay que situarla tal vez en los años que median entre las últimas décadas del siglo I y las primeras del siguiente.

Los antropónimos recogidos en el campo epigráfico son los correspondientes a una fase de latinización de los nombres personales, sobresaliendo el segundo nombre del personaje (Munigalicus) a quien se dedica la estela, posiblemente derivación de Munigalus ${ }^{4}$.

En cuanto al significado histórico de este monumento destaca el hecho de que el dedicante de la inscripción (Quadratus) constituye el único ejemplo hallado hasta la fecha en suelo asturiano sobre la existencia de libertos [Figeni(i) lib(ertus)] y, por ello, del posible establecimiento del esclavismo en Asturias en tiempos romanos (Cartes, 1997).

Podemos referirnos, entre otros, a la consagración a Lugovio Tabaliaeno de la entrada de la iglesia de Grases (Villaviciosa) (Mangas, 1983) o la dedicatoria a Júpiter descubierta en el altar mayor del recinto eclesial de San Vicente de Serrapio (Aller) ${ }^{5}$; con respecto al primer caso no nos parece suficientemente fundamentada la posibilidad de que se trate de una inscripción de carácter funerario y no votivo (González y Marco, 2009).

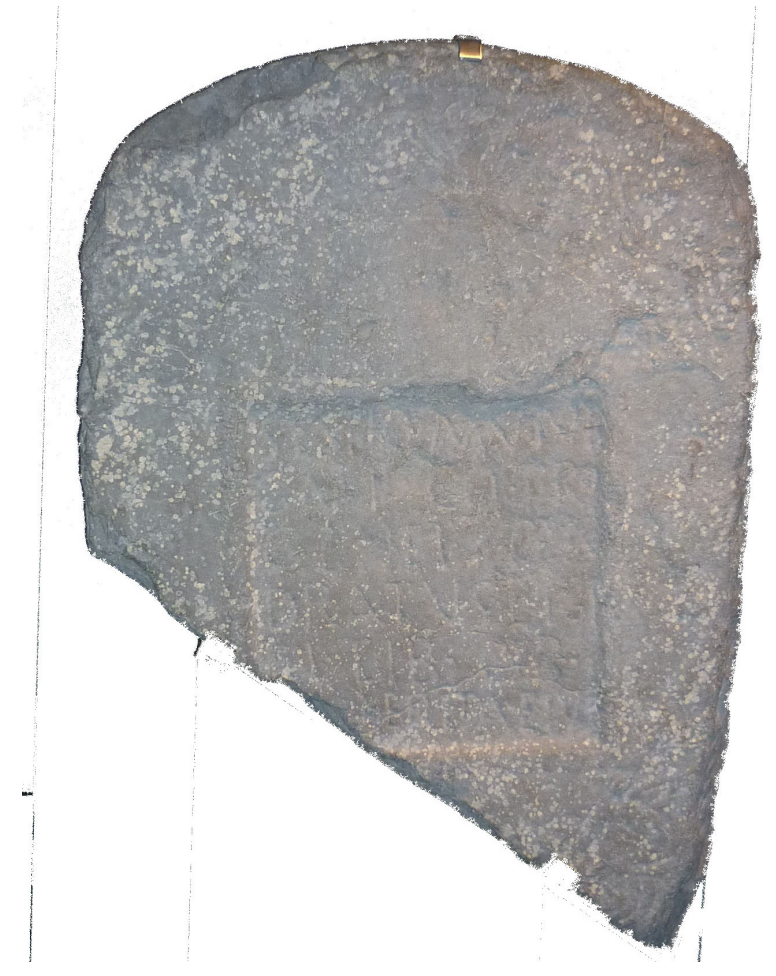

Figura 4: Estela de Valduno (Las Regueras) (Museo Arqueológico Provincial). Fuente: elaboración propia.

4 El contenido del campo epigráfico sería el siguiente: Sestio Muni/galico Pro/genei f(ilio)/ Qua/dratus Fige/ ni(i) lib(ertus) ob/ [plu(rima)] merita eius.

5 CIL II, 2697: Iovi Optimo/ et Maxsumo/sacrum Arro/ nidaeci et Col/ iacini pro sal/ ute sibi et su/ is posuerunt. 
Como en otros casos el documento se corresponde con un elemento pagano sincretizado, asociado a su vez a los centros de culto cristiano, perpetuando un centro religioso anterior enclavado en un edificio de la villa existente desde algunos siglos antes, ya que debajo de la iglesia actual se han hallado restos de unas termas romanas.

Resulta excepcional la ornamentación que configura la cenefa en entrelazo, similar a la correspondiente al epitafio de Pelsina hallado en Cornellana (González, 1949); sobresale el hecho de que, a ambos lados del campo epigráfico (a media altura) se representan en relieve dos vasijas con cuello alargado, una especie de lequithoi que quizás equivalgan a vasos funerarios (Diego Santos, 1985), en relación con los cultos de ultratumba (Figura 4).

La presencia de estos vasos cerámicos estilizados, imbuidos de ese carácter funerario, configuran, como la ornamentación de la estela en su conjunto, la expresión de un estilo artístico característico de los habitantes del Noroeste peninsular en tiempos romanos (Vega, 1973).

A un contexto funerario corresponde igualmente la estela discoidea hallada en La Lloraza (parroquia de Oles, concejo de Villaviciosa), en un terreno próximo a la iglesia y a la antigua malatería, a comienzos del siglo pasado (en la actualidad en el palacio de Lagüera, Priesca, adosada a la pared de poniente) (Diego Santos, 1985). Esta pieza mide $82 \mathrm{~cm}$. de altura por 40 de anchura en el disco superior y una anchura mínima de $19 \mathrm{~cm}$. en la base.

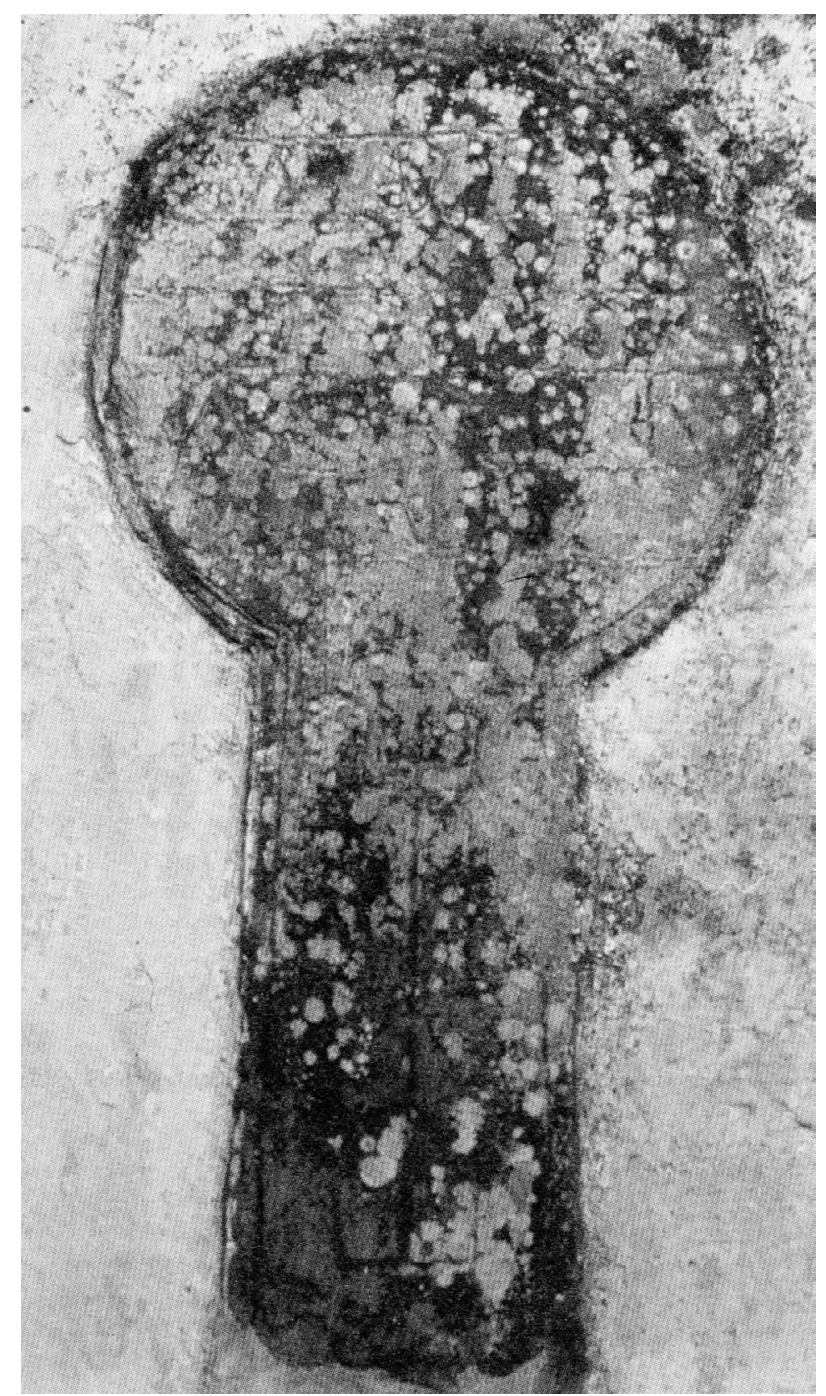

Figura 5: Estela discoidea de La Lloraza (Villaviciosa) (Diego Santos, 1985). 
El estado de conservación de la pieza, hallada en un contexto de antiguas sepulturas cristianas, no permite una reconstrucción y lectura de su campo epigráfico al encontrarse las letras muy gastadas. Puesto que el círculo superior del monumento parece apoyarse sobre una especie de trípode (dibujo estilizado a base de una línea recta y dos semirrectas al inicio y final de la misma, ocupando la parte central del soporte), es lógico pensar que nos hallamos ante un epitafio inscrito en una estela discoidea, intentando manifestar con ello que el sol podía cumplir la función de psicopompo que se descubre en algunas lápidas del oriente asturiano con relación a los equinos, como las de Septimio Silón y Flavia, sin olvidar las funciones que el astro rey desarrollaría como revitalizador del difunto al amanecer de cada día (Santos, 2013) (Figura 5).

Junto a este disco solar que envuelve el epitafio destaca la representación del vástago de la piedra, con algún sentido simbólico, comparable al del trípode figurado en la cabecera de la estela funeraria de Nicer (La Corredoira, Piantón, concejo de Vegadeo) (Santos, 2002). Con respecto al campo epigráfico el desgaste de las letras no permite su reconstrucción completa; de su finalidad funeraria se deduce que el dedicante figuraría al inicio del epitafio, dedicado a algún pariente del mismo, cuya muerte tendría lugar a los 44 años de edad 6 .

A ese mismo marco geográfico (La Lloraza, concejo de Villaviciosa) parece pertenecer la lápida funeraria de Aravo, ubicada en el mismo enclave (palacio de Lagüera en Priesca). El campo epigráfico se enmarca en cuatro renglones, acotados por cinco líneas rectas, permitiendo una reconstrucción fiable del mismo (González, 1997) ${ }^{7}$. El documento mide $40 \mathrm{~cm}$. de alto por 26 de ancho, sin poder calibrar su grosor al hallarse empotrada la pieza.

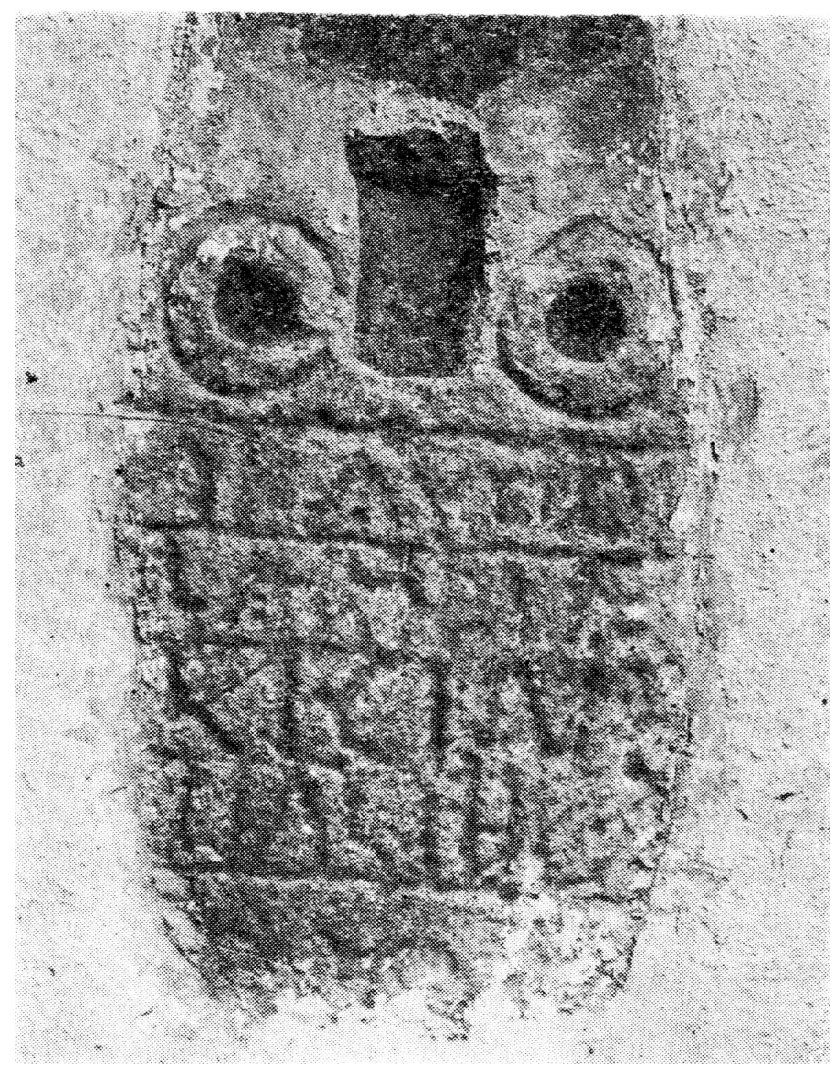

Figura 6: Monumento funerario de Aravo hallado en La Lloraza (Villaviciosa) (Diego Santos, 1985).

6 Las letras legibles en el interior del disco solar nos darían la siguiente reconstrucción: ...AV .V/R.S... IV./ ... V.SV./A.. V C.R/AN XLIV.

7 La reconstrucción del epígrafe es la siguiente: Aravo Oi/ laridu(m)/ Licini(i)/f(ilio) a(nnorum) LI h(oc) I(oco) s(itus). 
La nomenclatura nominal de los personajes que se registran en el monumento (Aravus y Licinius) resulta bastante frecuente en el Norte hispano, sobresaliendo la iconografía de su parte superior: por encima del campo epigráfico hay un pequeño nicho (Diego Santos, 1985) que en nuestra opinión difícilmente podría estar destinado a acoger las cenizas del difunto. Además, dispone de círculos rebajados a ambos lados (especie de ojos rodeados por circunferencias). Quizás estos círculos (oculares o no), por su ubicación en la zona superior del epitafio, contasen con alguna finalidad simbólica en conexión con el mundo de ultratumba (Figura 6).

En su interior es posible que se colocasen unas figuritas a manera de ídolos (Fernández Ochoa, 1982), posiblemente comparables con los ushebtis egipcios como representaciones mágicas de esos servidores que en el inframundo velarían por la alimentación y la vida del muerto. Ejemplos evidentes de tales figuraciones mágicas parecen asociarse claramente al hallazgo de las dos estelas funerarias de El Forniellu (Villaviciosa) (Fernández, 1926). Dicha representación iconográfica respondería a objetivos que sobrepasarían el mero valor ornamental de las figuraciones, pudiendo identificarse tal vez con representaciones solares en el marco del mundo del más allá.

Igualmente, y en ese mismo contexto geográfico, se enmarca la estela de Bodes (parroquia de Collía), en el concejo de Parres ${ }^{8}$. El epitafio del difunto (Bovecio) se rodea de una especie de círculo, enmarcado a su vez en una línea semicircular, aprovechando la tipología y forma de la piedra (discoidea), al tiempo que su contenido (campo epigráfico rebajado en el monumento) se estructura en siete líneas (la última de ellas ilegible), apoyadas sobre renglones de separación (González, 1997). Es posible que se haya producido un cierto desajuste en la concordancia de los nombres y la filiación (Vives, 1969).

Los intentos por reconstruir la última de tales líneas como aera o $m(e m) o r i a(m) ~ c(o n s u l a t u)$ (Cabal, 1953; Fita, 1912) no parecen especialmente adecuados, a pesar de que tampoco resulte posible considerar que en dicho renglón figurarían signos astrales vinculados al más allá. Esa misma tipología nos vincula con una representación solar, tan evidente en otras estelas de idéntica naturaleza (Figura 7) (Santos, 2013).

Por su parte la representación de las $\mathrm{V}$ como $\mathrm{U}$ tal vez nos lleve a datar este monumento ya en una etapa bastante avanzada de tiempos romanos, algo que parece deducirse también del formulario que encabeza el epitafio (M PD M), similar al de la estela sepulcral de Ammia Caelionica (quizás los comedios del siglo III d.C.).

En cuanto a la nomenclatura de los nombres personales resulta común a los antropónimos de la zona: así, Bovecius, se nos muestra en algunas inscripciones vadinienses, como las correspondientes a La Velilla de Valdoré (Diego Santos, 1986; Iglesias, 1976) ${ }^{10}$ o a Crémenes (Albertos, 1981) $)^{11}$.

Con respecto a Bode, antropónimo del padre, puede tratarse del genitivo Bod(a)e en lugar de un supuesto Boderus, como podemos observar en la lápida leonesa de La Remolina (Blázquez, 1959; Iglesias, 1976) $)^{12}$.

Así pues, en el epitafio de Bovecio nos encontraríamos, desde el punto de vista morfológico, con la culminación de ese proceso del paso de las estelas discoideas como meras representaciones solares ( $\mathrm{y}$ al mismo tiempo indicativo funerario de los lugares de enterramiento de carácter colectivo) a su conversión en lugar de acogida del difunto de forma individual y su relación con el inframundo y el renacer a la vida diaria, lo que equivale a que nos hallaríamos ante el paso de una mera

$8 \mathrm{CIL} \mathrm{II,} 2707$ = 5729: M(onumentum) p(ositum) d(iis) m(anibus)/ Bovecio Bode(ri) [f(ilius)]/ cives org(e) nom(escus)/ ex gente Pemb/ elor(um) vi(xit)? an(nos) LV posuit/ .........

9 CIL II, 5737 y 5749: [Monument]um/ p[ositum dib]us M/ anibus Scorcia o/ nnacau(m) Ammiae/ Caelionicae ex/gente Pentioru(m)/ anno(rum) XV/ pater filiae/ posuit/ do(mino) no(stro) Pos(tumo) IIII et Vict(orino) co(n) $s$ (ulibus).

10 CIL II, 5722: ...../ oi vadinien/sis Boveci(i) fili(i)/ an(norum) XXV.

11 CMLeón 84: M(onumentum) Bovec[io Fusc]/ o Que[sadioci f(ilio)]/ vad[iniensis an(norum)]/ XX...... Dacia/ Parnua $m$ (ater) $p$ (osuit).

$12 H A E n^{\circ} 1815$. 
decoración astral en las estelas discoideas (más antiguas) a una iconografía relacionada con la muerte y el mundo de ultratumba en esta tipología de estelas funerarias (Santos, 2016b).

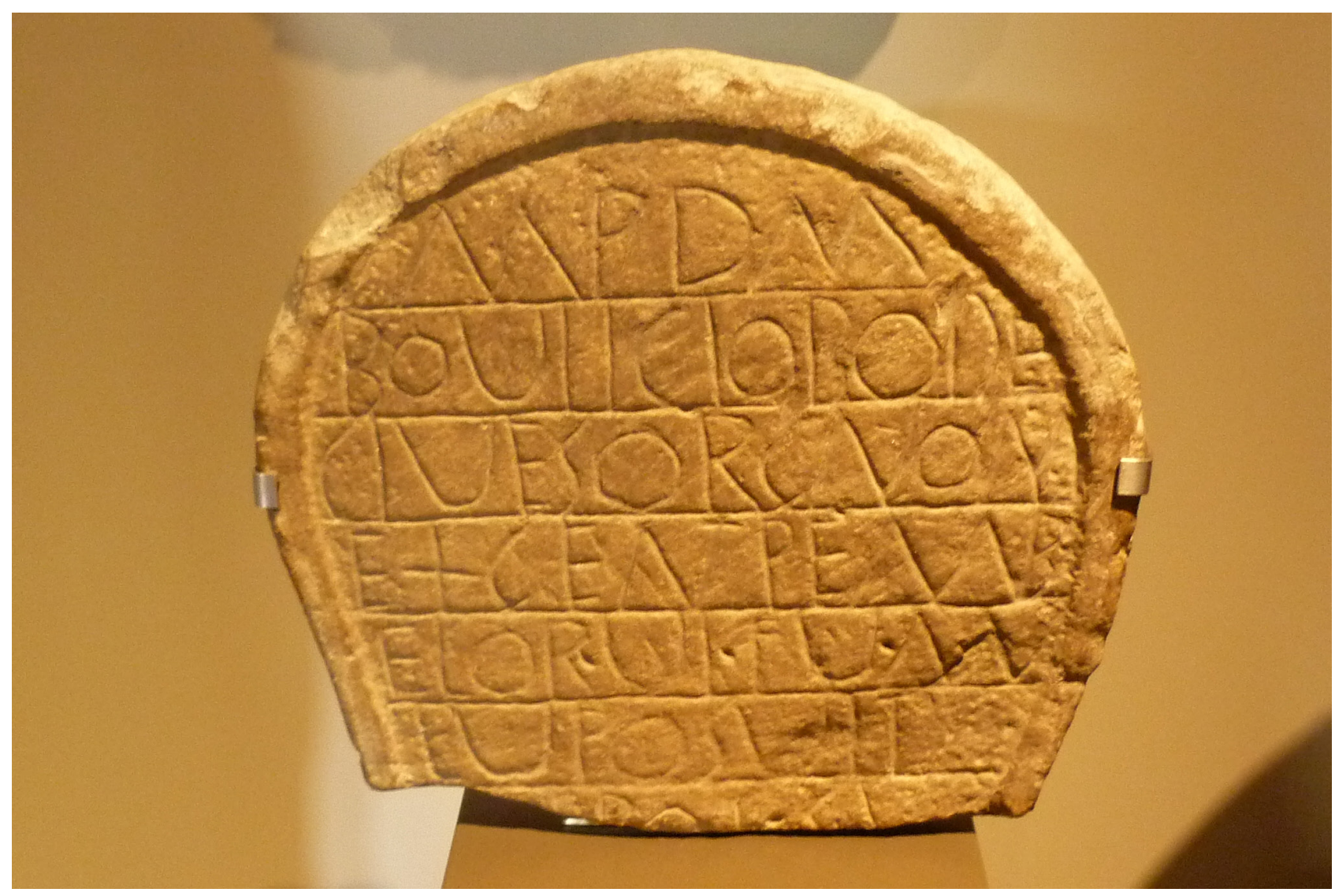

Figura 7: Lápida funeraria de Bovecio (Collía, Parres) (Museo Arqueológico Provincial). Fuente: elaboración propia.

\section{La lápida de Superia y su posible conexión con las estelas discoideas}

Algo similar parece haber sucedido con la estela dedicada a Superia, de reducidas dimensiones (aunque el epitafio se halla ubicado por debajo del disco solar), cuya procedencia se vincula a san Juan de Beleño (Ponga) (Santos, 2013). A pesar del estado de conservación (la parte superior y el lateral izquierdo bastante dañados), resulta muy expresiva por su morfología y por el propio epitafio (Escortell, 1975). Las dimensiones, reducidas debido a su fragmentación, son de 58 por 27 por 8 $\mathrm{cm}$. y en ellas se incluye una decoración peculiar en su cabecera y en su zona baja (Diego Santos, 1958) $)^{13}$.

Este monumento, sin embargo, no recoge el epitafio de la difunta en el interior del círculo solar que corona su parte superior, por lo que en realidad se aleja de la tipología propia de las estelas discoideas en cuanto tal. El documento en sí, a pesar de que cuenta con una parte del formulario pagano, ha sido considerado como cristiano por su contenido, siendo sus rasgos definitorios mucho menos evidentes que en el caso de las lápidas sepulcrales de Noreno ${ }^{14}$ y Magnentia (Diego Santos,

13 El contenido se reconstruye casi completo: D(iis) M(anibus) Peleserus (Peregrius)/ et Pompe(ia) Ar/ nunimoru(m)/ fili(a)e su(a)e pien/ tis(s)im(a)e Supe/ [ri(a)e] anno(rum) XV p/lu(s) minus/ [a]et[atis] nove(m). 14 CIL II.5745: X(ristus) A(Ifa) W(omega)/ una cruz (+)/ in m(emoria) s(ancta) mor/ tu(u)s an(n)oru(m)/ septe $(m)$ mise/ ravit r(elictos) paren/ tes Norenu/s. 
$1985)^{15}$

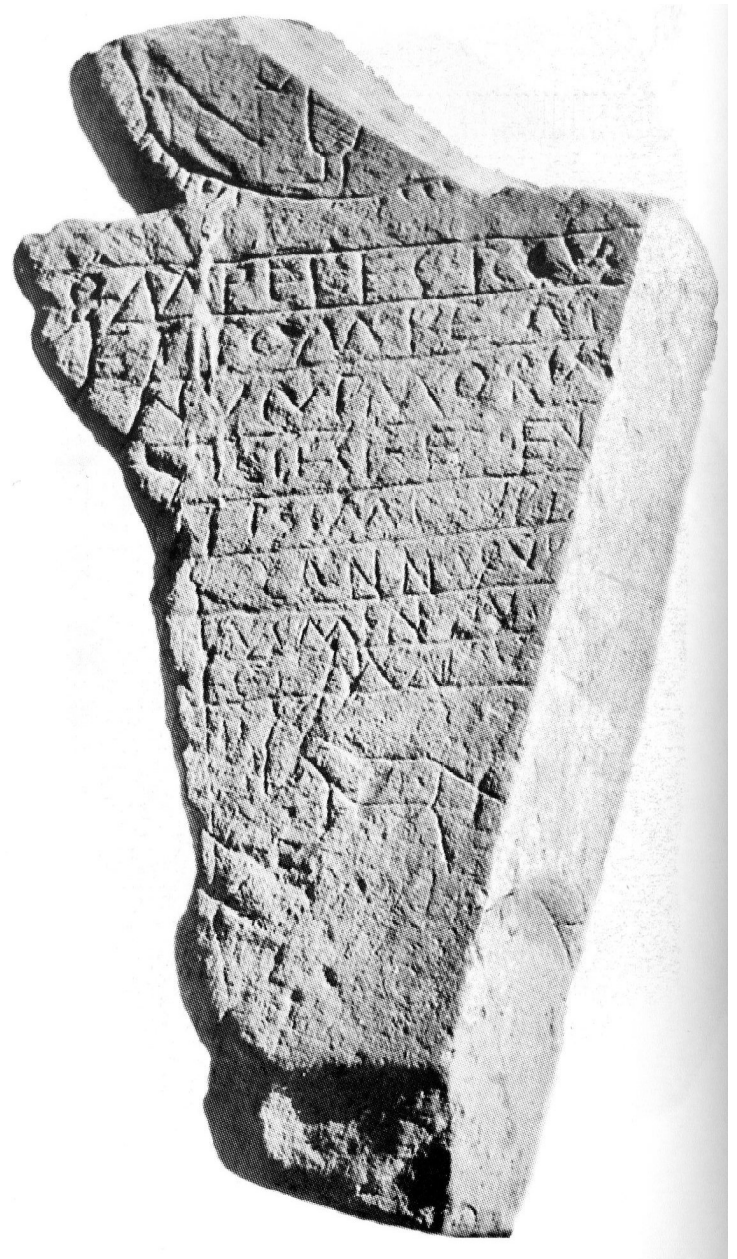

Figura 8: Estela sepulcral de Superia (Beleño, Ponga) (Diego Santos, 1985).

Algunos investigadores (Vives, 1969) consideran que serían igualmente cristianas otras dos inscripciones halladas en territorio asturiano y en la actualidad en paradero desconocido, puesto que en su campo epigráfico presentarían la fórmula memoriam posuit (o posuit memoriam) (Santos, 2014).

La datación de la inscripción de Superia parece ser tardía de acuerdo con una serie de aspectos vinculados al contenido del epitafio: la presencia de D.M. en lugar de DIS MANIBUS, la adaptación del campo epigráfico entre líneas horizontales y la expresión plus minus para referirse a la edad de la fallecida se dataría en la segunda parte del siglo II d.C. o en las décadas iniciales del siguiente (Figura 8).

Por otro lado la fragmentación del monumento ha hecho desaparecer buena parte del círculo de su cabecera (sin duda figuración del disco solar), por lo que en la actualidad sólo resulta visible la parte baja de una figura antropomorfa (¿la difunta?), figurada con la mano derecha en un bastón. La escena se completa con la representación de un animal de pequeñas dimensiones, tal vez identificable con una vaca. Comparando la presencia del caballo unido al ciervo de la estela funeraria de Septimio Silón (CIL II, 5735) con la figura humana más bóvido de ésta, podemos pensar en el pastoreo y/o la caza como actividades desplegadas en el otro mundo para mantener vivos a los difuntos. Unos rayos diminutos, tal vez correspondientes a la representación del disco solar, se

15 Magnen/ tia excedit/ annoru(m) v(itae)/ int(ra) IXXV/ ex domu d/ ominica. 
desgajan de un círculo que envolvería a las figuras.

Ahora bien, la ornamentación de esta escena parece combinar la figuración del sol con la humana de su interior (quizás en un ambiente pastoril), añadiéndose a ello la silueta en la parte izquierda, hacia la que parece dirigirse un equino, mostrando los rasgos de un árbol, del que solo algunas de sus ramas se dirigen hacia arriba (conexión entre el árbol y la palma con las inscripciones funerarias).

\section{Reflexiones finales}

Los documentos epigráficos que acabamos de analizar (todos ellos imbuidos de un sentido funerario) nos permiten descubrir ciertos rasgos comunes, conectados con el mundo de ultratumba, aunque algunos se puedan referir a los años previos al paso de la vida a la muerte (en ese ámbito se pueden considerar las escenas e iconografía de las actividades vinculadas a la ganadería).

Sobresale, en primer lugar, el hecho de que no se trata de piezas descubiertas en una zona concreta del actual Principado de Asturias sino que dichos ejemplares se han hallado esparcidos. En su parte oriental apareció la inscripción funeraria de Collía -Parres- dedicada a Bovecio en territorio de los orgenomescos. En el sector centro-oriental se hallan la estela anepígrafa de Duesos (Caravia) y el epitafio de Superia de san Juan de Beleño (Ponga). En la parte central contamos con los dos de La Lloraza (Villaviciosa), la estela anepígrafa y la dedicatoria funeraria a Aravo, así como la inscripción de Valduno (Las Regueras). En el sector centro-occidental se cuenta con la lápida de Pelsina en Cornellana (Salas) y, finalmente, al oeste de la región se ubica la estela discoidea asociada al recinto castreño de Coaña en el suelo habitado por la población galaica de los albiones.

Del análisis de su morfología y campo epigráfico, cuando no se corresponden con monumentos anepígrafos, se deduce que el rito funerario de mayor arraigo se vincularía con la práctica de la inhumación, dado que el soporte de los epitafios nos ofrece su parte inferior sin labrar, seguramente por hundirse en la tierra por encima de la tumba (monumentum) del difunto.

En este contexto hemos de incluir posiblemente también (intentando solucionar además el problema conectado con el enterramiento de los astures castreños) las estelas discoideas, anepígrafas en una primera fase pero que con posterioridad, ya en tiempos romanos, reconvertirían su simple decoración astral en lugar de acogida del epitafio del difunto.

Dichos documentos constituyen una realidad que, como elemento transversal, se vertebra a lo largo de tres fases históricas diferentes:

- en una primera etapa (época castreña anterromana) se trataría de piezas anepígrafas (Coaña -La Lloraza (Villaviciosa)- Duesos (Caravia)- Santibáñez de la Fuente (Aller);

- en tiempos romanos este tipo de monumentos pasaría a acoger el epitafio en el disco solar (como, por ejemplo, la estela funeraria de Bovecio en Collía, concejo de Parres);

- y, por último, acabarían por decorarse profusamente con la representación de la cruz en ambas caras (cristianas visigodo-medievales).

Los monumentos que recogen el campo epigráfico enmarcado en el disco solar, como el de Bovecio, se pueden considerar en cierto sentido como inscripciones oicomorfas, no tanto por su tipología (morfología) cuanto por vincularse directamente con la recepción del difunto una vez fallecido y convertirse en expresión de la perduración (pervivencia) de tales personajes en el mundo de ultratumba.

Sobresale la configuración a base de figuras astrales, en especial la iconografía solar; dicha representación parece implicar una referencia directa al más allá, constituyendo un trasunto de esa regeneración que la salida diaria del astro rey lleva a cabo para que la vida brote de nuevo para quienes residen en el inframundo (el sol constituye el mejor elemento de unión entre el cielo y la tierra, es decir entre este mundo y el otro, o, lo que es lo mismo, lo que representaba para los habitantes de la Asturias antigua la conexión entre esta vida y la supervivencia en el inframundo).

En este contexto las estelas discoideas, y su continuidad a lo largo de los siglos (desde la 
época prerromana a la medieval), nos permiten contemplar ese sentido funerario que encierra la representación del disco solar:

- en una primera fase tal vez como simple indicativo del lugar correspondiente al enterramiento colectivo de los difuntos en tiempos prerromanos;

- a continuación (ya en época romana) como centro de acogida del alma del fallecido al rodearlo con su superficie y protegerlo con vistas a su supervivencia en la otra vida;

- y, finalmente (en los primeros siglos del cristianismo, ya en el período visigodo-medieval), ahondando en estos mismos objetivos, en parte tras haberlos asimilado a través del sincretismo, así como introduciendo la cruz como elemento innovador respecto a las creencias tradicionales anteriores.

Tal vez el ejemplo más representativo lo constituya el epitafio de Bovecio, en cuyo monumento nos encontraríamos, desde el punto de vista morfológico, con la culminación de ese proceso del paso de las estelas discoideas consideradas como meras representaciones solares (indicio evidente del arraigo de la religiosidad naturalista) a su conversión en lugar de acogida del difunto y su relación (protección) con el inframundo y el renacer de cada día, pasando a acentuarse ese sentido de continuidad que el astro rey y su figuración en las estelas traería consigo.

Nos hallaríamos, por consiguiente, ante el paso que se produce desde una mera decoración astral recogida en las estelas discoideas (las más antiguas, casi con toda seguridad de tiempos prerromanos) a una iconografía vinculada a la muerte y al mundo de ultratumba en las estelas funerarias de este tipo en época romana, asumiendo con posterioridad ese sentido iconográfico de carácter funerario tradicional las correspondientes a los primeros siglos del cristianismo (tiempos visigodo-medievales).

\section{Abreviaturas}

CIL II. Hübner, E. Corpus Inscriptionum Latinarum, II. Hispania. Berlín: Berlín-Brandenburg Academy of Sciences and Humanities. 1869.

CMLeón. Gómez Moreno, M. Catálogo monumental de España. Provincia de León. Madrid: Ministerio de Instrucción Pública y Bellas Artes. 1963.

HAE. Hispania Antiqua Epigraphica. Madrid: Instituto de Arqueología y Prehistoria Rodrigo Caro. (1950--).

\section{Bibliografía}

Abascal, J. M. (1994). Los nombres personales en las inscripciones latinas de Hispania. Murcia: Universidad.

Albertos, M. ${ }^{a}$ L. (1981). Organizaciones suprafamiliares en la Hispania antigua II. Boletín del Seminario de Estudios de Arte y Arqueología de Valladolid, 47, 208-214.

Blázquez, J. M. (1959). Caballo y ultratumba en la Península Hispánica. Ampurias, 21, 281-302.

Bohigas, R.; Unzueta, M.; Cancelo, C. y Molinero, J. T. (2004). La fusayola pétrea del oppidum (s) amanorum y su decoración: un esquema común a las estelas cántabras. Actas del VII Congreso Internacional de Estelas Funerarias (Santander, 24-26 de octubre de 2002). Santander, I, 371382.

Bohigas, R., Chatruch, C. y García, M. (2004). Dos nuevas estelas discoidales de cronología medieval en Santibáñez (Cabezón de la Sal). Actas del VII Congreso Internacional de Estelas Funerarias (Santander, 24-26 de octubre de 2002). Santander, II, 571-584.

Cabal, C. (1953). La Asturias que venció Roma. Oviedo: Instituto de Estudios Asturianos.

Carballo, J. (1948). Estelas gigantes de Cantabria. Cuadernos de Estudios Gallegos, 3, 7-21.

Cartes, E. (1997). Lápida funeraria de Sestio Munigálico. Nuestro Museo, 1, 199-208.

Cerezo, T. y Vega, J. R. (2004). Acerca de la estelas de Santander. En Actas del VII Congreso 
Internacional de Estelas Funerarias (Santander, 24-26 de octubre de 2002), (pp. 551-560). Santander: Fundación Marcelino Botín.

Diego Santos, F. (1958). Dos inscripciones inéditas de Asturias. Actas del I Congreso Español de Estudios Clásicos (pp. 479-483). Madrid: Sociedad Española de Estudios Clásicos.

Diego Santos, F. (1985). Epigrafía romana de Asturias. Oviedo: Instituto de Estudios Asturianos.

Diego Santos, F. (1986). Inscripciones romanas de la provincia de León. León: Diputación Provincial de León.

Diego Santos, F. (1994). Inscripciones medievales de Asturias. Oviedo: Consejería de Educación. Principado de Asturias.

Escortell, M. (1975). Catálogo de las salas de cultura romana del Museo Arqueológico de Oviedo. Oviedo: Museo Arqueológico.

Fernández, J.M. (1926). Las lápidas del Forniellu. Intento de interpretación. Diario Región, 19 de octubre.

Fernández Fuster, L. (1952). Un nuevo núcleo artístico en el Norte de España. Archivo Español de Arqueología, 25, 161-163.

Fernández, A. y Miyares, A. (1987). La estela de Duesos, Caravia. Boletín del Institudo de Estudios Asturianos, 124, 1035-1054.

Fernández Ochoa, C. (1982). Asturias en la época romana. Madrid: Universidad Autónoma.

Fita, F. (1912), Boletín de la Real Academia de la Historia, 61, 452 y 477.

Gómez Ortiz, J. (1938). Dos estelas discoideas de Cantabria. XV Congreso Asociación Española para el progreso de las ciencias (pp. 1-15). Santander: AEPC.

González, J. M. (1949). La estela de Valduno. Boletín del Instituto de Estudios Asturianos, 7, 3-9.

González, J. M. (1951). Un fragmento de la estela de Cornellana. Boletín del Instituto de Estudios Asturianos, 13, 237-239.

González, M. ${ }^{a}$ C. (1997). Los astures y los cántabros vadinienses. Vitoria: Universidad del País Vasco.

González, M. ${ }^{a}$ C. y Marco, F. (2009). Divinidades y devotos indígenas en la Tarraconensis: las dedicaciones colectivas. Palaeohispanica, 9, 65-81.

Iglesias, J. M. (1976). Epigrafía cántabra. Santander: Institución Cultural de Cantabria.

Jordá, F. (1977). La cultura de los castros y la tardía romanización de Asturias. En Actas del Coloquio sobre el bimilenario de Lugo (pp. 29-40). Lugo: Diputación Provincial.

Mangas, J. (1983). La difusión de la religión romana en Asturias. Indigenismo y romanización en el conventus Asturum (pp. 165-177). Madrid-Oviedo: Ministerio de Cultura-Universidad de Oviedo.

Millán, C. (1941). Estela funeraria de Castiello. Atlantis, 16, 185-192.

Peralta, E. (1989). Estelas discoideas de Cantabria y su cronología. En Estelas discoideas de la Península Ibérica (pp. 447-469). Madrid: Ediciones Istmo.

Peralta, E. (1990). Estelas discoideas de Cantabria. Estelas discoideas de la Península Ibérica (pp. 425-446). Oviedo: Ediciones Istmo.

Peralta, E. (1996). Las estelas discoideas gigantes de Cantabria. En La arqueología de los cántabros. Actas de la primera reunión sobre la Edad del Hierro en Cantabria (pp. 21-63). Santander: Fundación Marcelino Botín.

Peralta, E. (2004). Indigenismo y romanidad en las estelas funerarias de la Cantabria antigua. En Actas del VII Congreso Internacional de Estelas Funerarias (Santander, 24-26 de octubre de 2002) (pp. 257-356). Santander: Fundación Marcelino Botín.

Santos, N. (2002). La inscripción de Nicer hallada en La Corredoira (Vegadeo) y los albiones (galaicos) del Occidente de Asturias. En En torno al bimilenario del Eo (pp. 279-298). Oviedo: Foro Cultural del Noroeste.

Santos, N. (2013). Costumbres funerarias y vida de ultratumba en la Asturias antigua. MadridSalamanca: Signifer Libros.

Santos, N. (2014). La lápida funeraria de Magnentia y los orígenes del cristianismo en el Oriente de 
Asturias. Tiempo y sociedad, 17, 33-52.

Santos, N. (2016a). El epitafio de Bovecio (Collía, Parres) y la asociación del culto solar con el mundo de ultratumba en Asturias antigua. Tiempo y Sociedad, 23, 7-26.

Santos, N. (2016b). Representaciones solares en la epigrafía romana de Asturias. Hispania Antiqua, 40, 135-167.

Santos, N. (2017). Inscripciones romanas de carácter votivo y primitivos lugares de culto cristiano en Asturias. En Escrito sobre piedra. Estudios de epigrafía e historia del noroeste de la Península Ibérica (pp. 7-56). Oviedo: Asturiensis Regnum Territorium.

Vega, M. (1973). Cerámica común romana del Mediterráneo occidental. Barcelona: Publicaciones eventuales.

Vives, J. (1969). Inscripciones cristianas de la España romana y visigoda. Barcelona: C.S.I.C. Instituto Jerónimo Zurita. 


\section{Panta Rei}

PANTA REI es una revista digital de investigación orientada a la Historia y otras ciencias afines. Su principal objetivo es la transmisión del conocimiento científico, dando una oportunidad también a los jóvenes investigadores que quieren abrirse camino en el estudio de las ciencias humanas y sociales. Se compone de estudios originales relacionados con la disciplina histórica así como su didáctica y difusión. Las diferentes secciones que componen la revista son: artículos de investigación, entrevistas a profesionales, recensiones de monografías de actualidad y crónicas de congresos o eventos científicos relevantes.

Todos los artículos publicados son objeto de un proceso de revisión a cargo de un mínimo de dos evaluadores, que se consideran expertos en el ámbito temático del artículo propuesto. Nuestro deseo es poder ofrecer unos contenidos rigurosos, de calidad y de interés.

EI CEPOAT (Centro de Estudios del Próximo Oriente y la Antigüedad Tardía de la Universidad de Murcia) es la institución encargada de la coordinación y gestión de la revista, desde donde anualmente se lanzará la convocatoria para aquellos que estén interesados en publicar sus trabajos, siempre relacionados con la Historia, Arqueología, Historia del Arte, Didáctica de las Ciencias Sociales, etc.

PANTA REI is a digital journal focused on History and other sciences related to it. Its main objective is the transmission of scientific knowledge by giving also an opportunity to young researchers who want to make their way in the study of human and social sciences. It is composed by original studies related to History, as well as its didactics and promotion. The different sections of this journal are: research articles, interviews to professionals, recensions on monographs about current issues and reports about congresses or relevant scientific events.

All the articles published are subject to a revision process carried out by a minimum of two reviewers who are considered to be experts in the field of the article proposed. Our wish is to offer rigorous contents with quality and being of interest to the reader.

CEPOAT (Centre of Studies of the Middle East and Late Antiquity of the University of Murcia) is the institution in charge of the coordination and management of this journal. This is the centre from where the call for papers will be launched for all the people interested in publishing their papers, always related to History, Archeology, Art History, Didactics of the Social Sciences, etc. 


\section{Normas de Publicación}

El autor se compromete a enviar trabajos originales, que no se encuentren publicados en otras revistas ni en otros idiomas. Así mismo, el mismo artículo no podrá ser presentado en otras revistas mientras dure el proceso de evaluación.

\section{Envío y presentación de originales}

Los artículos se enviarán exclusivamente a través del correo electrónico a la dirección pantarei@um.es. Los textos serán enviados en formato DOC y las imágenes en formato JPEG o TIFF, y con un tamaño mínimo de 2000 px. Éstas no aparecerán incorporadas en el texto, sino enviadas en archivo aparte y correctamente numeradas según su posición en el texto. Junto al trabajo, se rellenará y enviará un documento aparte en el que se especifiquen los datos del autor siguiendo el modelo disponible en la página Web de la revista.

Para la redacción de los trabajos se tendrá en cuenta el Manual de la American Psychological Association, en su sexta edición. La extensión máxima de los trabajos será de 30 páginas. La tipografía será Arial 11, con interlineado sencillo y sin espacio alguno entre párrafos. El texto deberá ir justificado a ambos márgenes y sin sangría en los primeros párrafos. Los márgenes serán de $2,50 \mathrm{~cm}$. En los casos en los que fuera necesario incorporar notas, éstas irán a pie de página, enumeradas consecutivamente, con tipografía Arial 10, interlineado sencillo y justificadas a ambos márgenes.

Una información más detallada se encuentra disponible en la página http://www.um.es/cepoat/ pantarei.

\section{Proceso de valoración y evaluación}

Una vez recibidos los trabajos, la Revista realizará una primera valoración. Si el trabajo enviado se ajusta a las normas de presentación propuestas, la temática es coincidente con la línea editorial de la revista y posee la calidad científica necesaria, será remitido al consejo asesor para una primera evaluación. Si no es así en este primer paso se puede rechazar directamente los documentos que incumplan claramente la línea editorial.

Será el Consejo Asesor quien indique a la revista la originalidad, relevancia, estructura, redacción, aparato bibliográfico, etc. del trabajo enviado y, para ello, se designará a dos revisores expertos externos que evaluarán cada uno de los trabajos, que pueden formar parte (o no) de este Consejo Asesor. La selección de los revisores se ajustará a la temática y características metodológicas del trabajo. El nombre y filiación de los autores serán eliminados del trabajo para su revisión, así como los revisores actuarán de manera anónima y confidencial.

Los revisores deberán rellenar un informe de evaluación que centrará su atención en aspectos tales como características formales, originalidad y novedad de los trabajos, relevancia de las propuestas y los resultados, calidad metodológica y validez científica.

Una vez terminado el proceso se decidirá la aceptación o no de los mismos y su publicación en el número que sea pertinente, así como las modificaciones susceptibles de ser realizadas para su final publicación. Dicha notificación se enviará únicamente por correo electrónico, en un plazo máximo de seis meses. 


\section{Publishing rules}

The author is committed to submit original papers not having been published in other reviews or in other languages. In this way, it is not allowed for the same paper to be presented in other reviews during the evaluation process.

\section{Submission and presentation of originals}

The articles will be exclusively submitted by email to pantarei@um.es. The texts will be submitted in DOC format and the images in JPEG or TIFF format, and with a minimum size of 2000 px. Images will not be integrated in the text but sent in another file and properly numbered according to their position in the text. Attached to the paper, a document will be filled out and sent where the author's data will be specified following the model available on the website.

The sixth edition of the Manual of the American Psychological Association will be taken into account for the writing of the papers. The length of the papers must not exceed 30 pages. Typography will be Arial 11 , with simple line spacing and no space between paragraphs. The text must be justified on both margins without indentation in the first paragraphs. Margins size will be $2.50 \mathrm{~cm}$. Where it could be necessary the incorporation of notes, they will be at the bottom of the page, consecutively numbered with typography Arial 10, simple line spacing and justified on both margins.

More detailed information is available on the website: http://www.um.es/cepoat/pantarei.

\section{Examination and assessment process}

The Journal will submit the papers to a first examination once received. If the paper follows the presentation guidelines, the subject agrees with the editorial line of this journal, and possess the scientific quality required, it will be sent to the advisory council for a first assessment. If not, the documents which clearly fail to complete the editorial line may be rejected straightaway in this first step.

The Advisory Council will indicate the originality, relevance, structure, writing, bibliography, etc. of the text to the journal; for this purpose, two outside experts will be designated to review the papers; these experts can be (or not) part of this Advisory Council. The selection of the experts will adjust to the subject and methodological characteristics of the paper. Name and affiliation of the author will be eliminated from the text for its review, in this way experts will act anonymously and confidentially.

The experts will fill out an assessment report which will focus on aspects such as formal characteristics, originality and novelty of the papers, relevance and results of the proposal, methodological quality and scientific validity.

Once the process is finished, the acceptance or not of the papers and its publication in the corresponding edition will be decided, as well as the modifications that may be done for its final publication. This notification will be sent by email within 6 months maximum. 



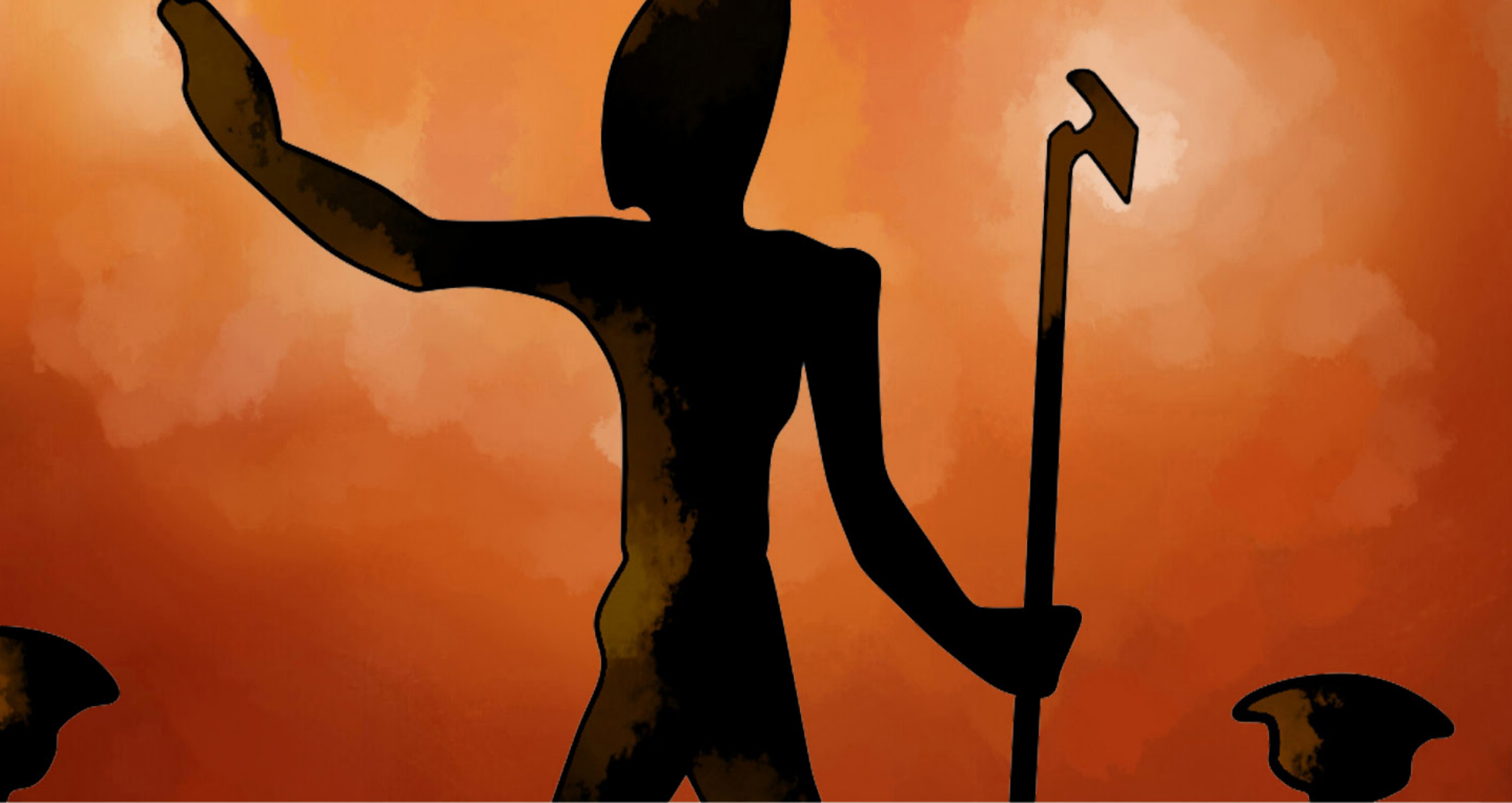

\section{cepoAt}

UNIVERSIDAD DE MURCIA

centro de estudios del

próximo oriente y la

antigüedad tardía 